\title{
Twin Anemia Polycythemia Sequence in a Dichorionic Twin Pregnancy Leading to Severe Cerebral Injury in the Recipient
}

\author{
Lisanne S.A. Tollenaar ${ }^{a}$ Sandra A. Prins ${ }^{b}$ Sabine Beuger ${ }^{c}$ Femke Slaghekke $^{a}$ \\ Dick Oepkes $^{a}$ Enrico Lopriore ${ }^{d}$
}

aDepartment of Obstetrics, Leiden University Medical Center, Leiden, The Netherlands; ${ }^{\mathrm{b}}$ Department of Pediatrics, Amsterdam University Medical Center, Amsterdam, The Netherlands; ' ${ }^{D}$ Department of Pediatrics, Noordwest Ziekenhuisgroep Den Helder, Den Helder, The Netherlands; ${ }^{\mathrm{d} D e p a r t m e n t}$ of Pediatrics, Leiden University Medical Center, Leiden, The Netherlands

\section{What Is Already Known}

- Monochorionic twins share 1 placenta and have placental anastomoses connecting the 2 fetal circulations, whereas dichorionic twins have separate placentas without anastomoses.

- Twin anemia polycythemia sequence can occur in monochorionic twins as the result of chronic unbalanced feto-fetal transfusion through minuscule placental anastomoses.

\section{New Insights}

- In rare situations, dichorionic twins may also have small placental anastomoses which can lead to twin anemia polycythemia sequence.

- In dichorionic twins with large intertwin hemoglobin difference, measurement of reticulocyte count and placental injection is required to assess or rule out the presence and nature of feto-fetal transfusion pathology.

\section{Keywords}

Dichorionic twin - Monochorionic twin - Twin anemia polycythemia sequence $\cdot$ Placenta $\cdot$ Anastomoses $\cdot$ Cerebral injury

\section{Abstract \\ Twin anemia polycythemia sequence (TAPS) is a form of chronic imbalanced feto-fetal transfusion through minus-}

cule placental anastomoses leading to anemia in the TAPS donor and polycythemia in the TAPS recipient and has been reported only in monochorionic twins. We report a very unusual case of TAPS which developed in a dichorionic twin pair, born at a gestational age of $33^{+2}$. Twin 1 (recipient) was polycythemic and had a hemoglobin value of $22.4 \mathrm{~g} / \mathrm{dL}$, whereas twin 2 (donor) was anemic with a hemoglobin value of $9.8 \mathrm{~g} / \mathrm{dL}$ and an increased reticulocyte count (72\%o). Color dye injection of the placenta revealed the presence of a

$\begin{array}{ll}\text { karger@karger.com } & \begin{array}{l}\text { c } 2021 \text { The Author(s) } \\ \text { Published by S. Karger AG, Basel }\end{array} \\ \text { www.karger.com/fdt } & \begin{array}{l}\text { This is an Open Access article licensed under the Creative Commons } \\ \text { Attribution-NonCommercial-4.0 International License (CC BY-NC) } \\ \text { (http://www.karger.com/Services/OpenAccessLicense), applicable to } \\ \text { the online version of the article only. Usage and distribution for com- } \\ \text { mercial purposes requires written permission. }\end{array}\end{array}$

karger@karger.com

Karger

BOPEN ACCESS
(C) 2021 The Author(s)

This is an Open Access article licensed under the Creative Commons Attribution-NonCommercial-4.0 International License (CC BY-NC)
(http://www.karger.com/Services/OpenAccessLicense), applicable to mercial purposes requires written permission.
Lisanne S.A. Tollenaar

Department of Obstetrics

Leiden University Medical Center, Albinusdreef 2

NL-2333 ZA Leiden (The Netherlands)

l.s.a.tollenaar@lumc.nl 
deep-hidden small veno-venous anastomosis. Dichorionicity was confirmed on histologic examination. Aside from respiratory distress syndrome, the donor twin had an uncomplicated neonatal course. The recipient twin developed a post-hemorrhagic ventricular dilatation requiring treatment with a ventriculoperitoneal shunt and Rickham reservoir. This report shows that in dichorionic twins, placental anastomoses can be present, which can lead to the development of TAPS with severe consequences. Therefore, when a pale and plethoric dichorionic twin pair is born, a complete diagnostic work-up is required, including a full blood count with reticulocytes and placental injection, to investigate the presence and nature of potential underlying feto-fetal transfusion. Once the diagnosis of TAPS has been established, cerebral ultrasound, hearing screening, and long-term follow-up are strongly recommended as these twins have increased risk for severe cerebral injury, hearing loss, and long-term neurodevelopmental impairment. @ 2021 The Author(s)

Published by S. Karger AG, Basel

\section{Introduction}

A 22-year-old woman (G3P0) was pregnant with a dichorionic twin pregnancy. Dichorionicity was confirmed based on the lambda sign during the first-trimester ultrasound scan at her local hospital. Aside from gestational diabetes, the course of pregnancy was uneventful. Monthly ultrasound examination revealed normal amniotic fluids and adequate linear growth for both fetuses. Middle cerebral artery peak systolic velocity ultrasound Doppler measurements were not performed. At $32^{+6}$ weeks of gestation, the patient had premature uterine contractions for which corticosteroid therapy was administered. At $33^{+2}$ weeks' gestation, a cesarean section was performed for fetal distress on CTG registration. Two boys were born. Twin 1 had Apgar scores of 3/6/9, weighed 1,962, g and was plethoric (Fig. 1a). Twin 2 had an Apgar score of $5 / 8 / 8$, weighted 1,994 , g and was pale (Fig. 1b). A full blood count revealed a hemoglobin value of 22.4 and 9.8 $\mathrm{g} / \mathrm{dL}$ (normal range (p5-p95): 13-20 g/dL) for twin 1 (plethoric) and twin 2 (pale), respectively. Reticulocytes count was $72 \%$ in twin 2 (normal range $40-60 \%$ ). The reticulocyte count in twin 1 was not measured. In twin 2 , also a low leukocyte count $\left(6.2 \times 10^{9} / \mathrm{L}\right)$ and platelet count $\left(30 \times 10^{9} / \mathrm{L}\right)$ were detected. The inter-twin hemoglobin difference was $12.6 \mathrm{~g} / \mathrm{dL}$, raising the suspicion of an unbalanced feto-fetal transfusion. To reevaluate the chorionicity and examine the presence of placental anastomoses, the placenta was shipped to our hospital, which is the national referral center for fetal therapy and complicated twin pregnancies. The twins were transferred to an academic hospital nearby for respiratory support at the neonatal intensive care unit.

At macroscopic placental examination, a thick opaque intertwin placental membrane was observed, supporting the likelihood of a true dichorionic twin pregnancy (Fig. 2a), without evidence of placental anastomoses at first sight. To further examine the angioarchitecture of the placenta, color-dye injection of the placental vessels was performed. Dark blue color dye was used for the arteries, and pink color dye was used for the veins in twin
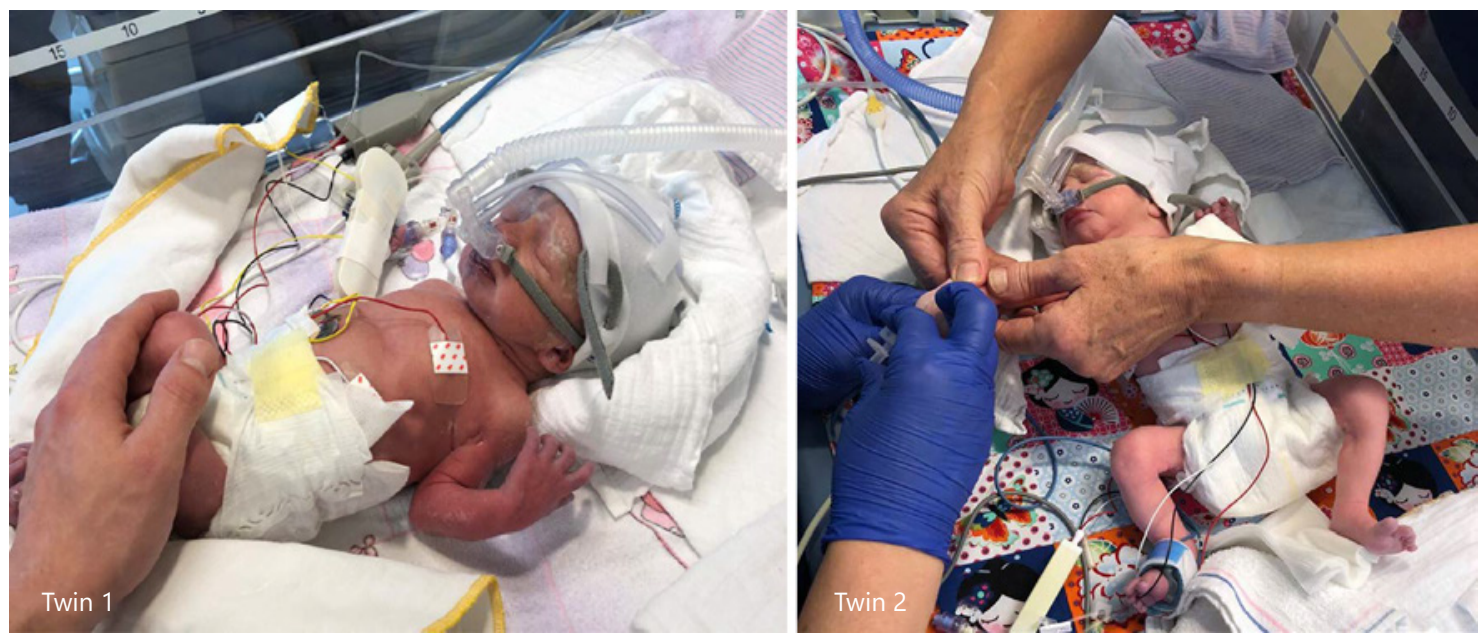

Fig. 1. a The plethoric polycythemic TAPS recipient. b The pale anemic TAPS donor. TAPS, twin anemia polycythemia sequence. 


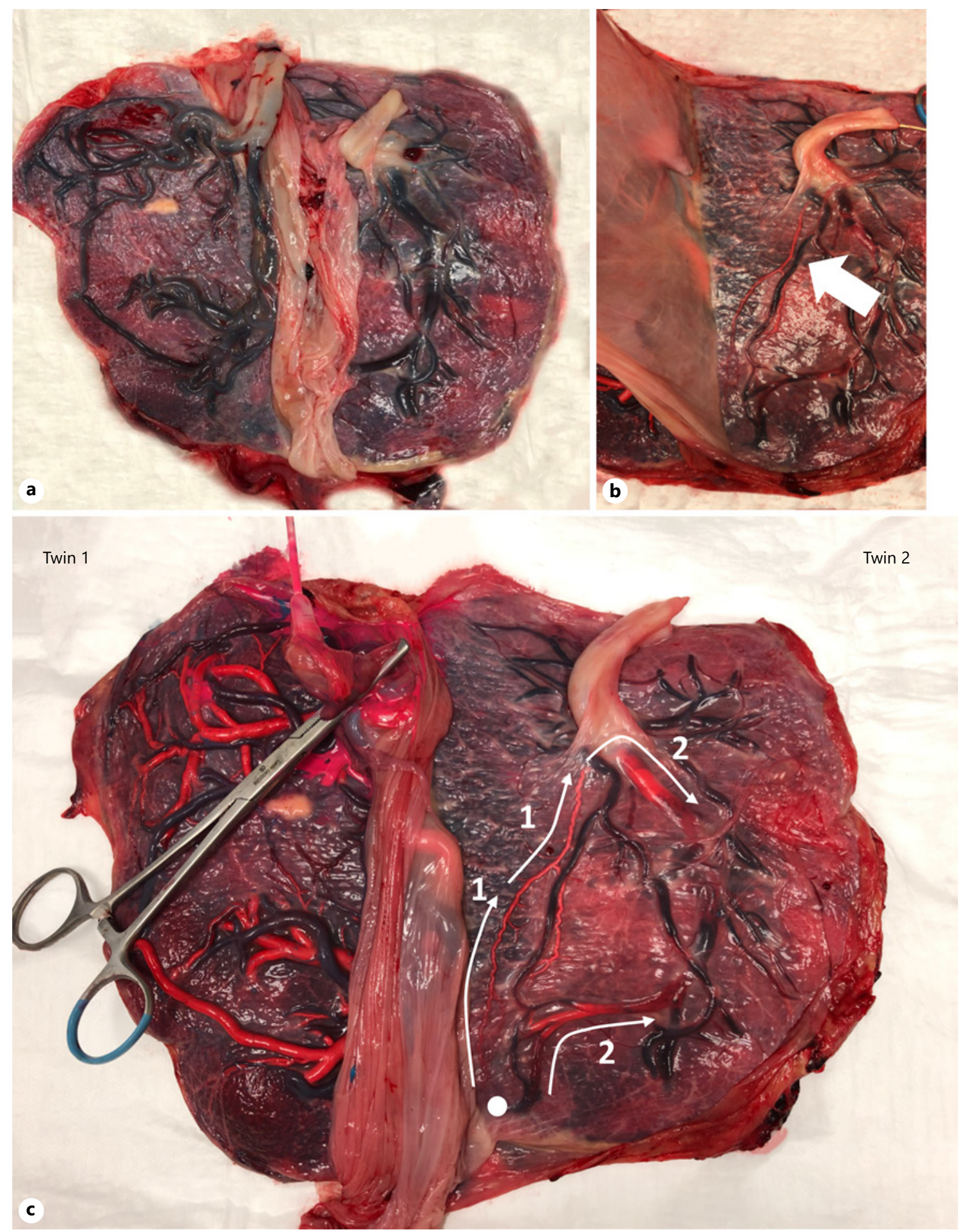

Fig. 2. a The placenta before color dye injection. In between the 2 placental shares, the thick intertwin membrane can be observed. b Close-up of the placental share of twin 2, just after injection of the venous circulation of twin 1 . The white arrow indicates the vein in which the red color dye, originating from the venous circulation of twin 1, first appeared. c Placenta midway through color dye in- jection of the venous circulation of twin 2. The white dot represents the point from which the red-color dye entered the venous circulation of twin 2 . The arrows indicate the direction of color dye flow. The numbers $(1,2)$ indicate the sequence of injection (the veins that are marked with a " 2 " turned red after the veins marked with " 1 ". 

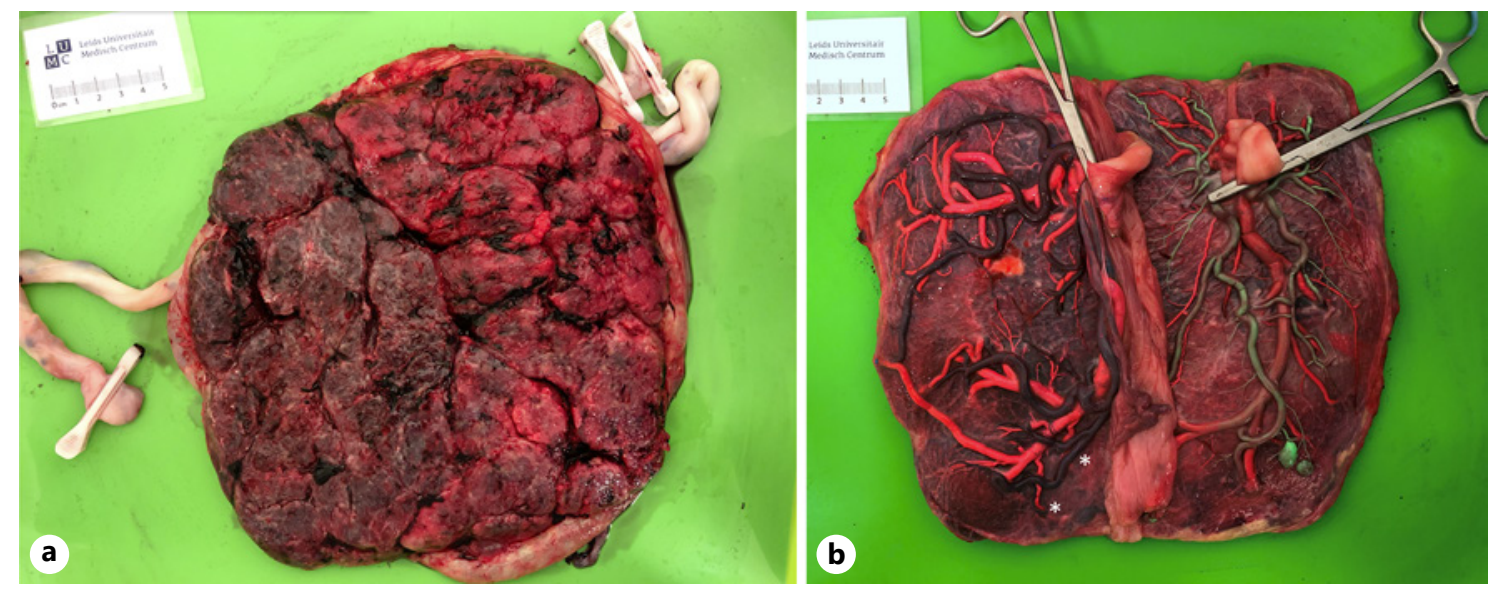

Fig. 3. a The maternal side of the placenta displaying a plethoric placental share for the TAPS recipient (twin 1) and a pale placental share for the TAPS donor (twin 2). $\mathbf{b}$ The placenta after color dye injection. The arteries of twin 1 are injected with blue-color dye, and the arteries of twin 2 are injected with green-color dye. The veins of twin 1 and twin 2 are injected with red-color dye. Stars indicate the veins from which the VV anastomosis might have arisen. TAPS, twin anemia polycythemia sequence; $\mathrm{VV}$, veno-venous.
1. After injection of $40 \mathrm{~mL}$ of pink color dye into the vein of twin 1, a subtle hint of pink color dye was observed in one of the distant small veins in the placental share of twin 2 (Fig. 2b), suggesting the presence of a deep-hidden small veno-venous (VV) anastomosis. To confirm the suspicion, more pink color dye was pumped into the venous circulation of twin 1 (Fig. 2c), hereby slowly achieving full injection of the venous placental circulation of twin 2. The arteries of twin 2 were injected with green color dye. No visible anastomoses were observed after the injection of both circulations was finished. The maternal side of the placenta showed a color difference, with a plethoric placental share for twin 1 and a pale placental share for twin 2, similar to their skin color (Fig. 3b). The color difference ratio between the 2 shares was 1.3 , measured using ImageJ version 1.53 (U.S. National Institutes of Health, Bethesda, MD, USA). To unveil the type and number of deep anastomoses, the placenta was injected with iobitridol contrast fluid and photographed under Xray. Unfortunately, this gained inconclusive results due to excessive leakage of fluid from the vessels into the adjacent placental tissue. Histologic examination of the intertwin membrane demonstrated the presence of 2 amniotic and 2 chorionic membranes, confirming the dichorionic nature of the twin pregnancy.

Based on the large hemoglobin difference $(>8 \mathrm{~g} / \mathrm{dL})$, the increased reticulocyte measure in the anemic infant, and the placental characteristics (small anastomosis and placental color difference), this dichorionic twin was diagnosed with twin anemia polycythemia sequence
(TAPS), with twin 1 being the TAPS recipient and twin 2 being the TAPS donor twin. Further management was carried out according to our protocol for TAPS twins, including a cerebral ultrasound, neonatal hearing screening, and long-term follow-up appointments.

\section{Neonatal Course}

The TAPS donor was diagnosed with respiratory distress syndrome grade 3-4 for which a total of 3 doses of exogenous surfactant was required. On day 2 , its hemoglobin and platelet levels had dropped to $7.1 \mathrm{~g} / \mathrm{dL}$ and 18 $\times 10^{9} / \mathrm{L}$, respectively, for which an erythrocyte and platelet transfusion was performed. Cerebral ultrasound (performed on days 1 and 4) showed no abnormalities. After 5 days at the neonatal intensive care unit, the donor twin was transferred to a step-down unit. After 4 weeks in the hospital, the boy was discharged to home. The TAPS recipient initially showed clinical signs of respiratory distress syndrome, but these resolved within the first $24 \mathrm{~h}$ after birth. Polycythemia was adequately treated with hyperhydration therapy. Cerebral ultrasound on day 1 revealed a unilateral intraventricular hemorrhage grade 2 [1], with mild posthemorrhagic ventricular dilatation and the presence of blood in third and fourth ventricle. This progressed toward a severe posthemorrhagic ventricular dilatation ( $>97$ th centile [2]) with periventricular echogenicities, for which treatment with a Rickham reservoir and a subsequent ventriculoperitoneal shunt was re- 
quired. After 8 weeks of hospital admission, the TAPS recipient was discharged home.

At 4 months of age, both boys are doing well. Neonatal hearing screening showed no abnormalities for both boys. The TAPS recipient will be seen regularly by the pediatric neurologist to evaluate neurologic development.

\section{Discussion}

We report an unusual case of TAPS in a dichorionic twin pair, leading to severe cerebral injury in the recipient twin. TAPS is known to result from chronic blood flow through minuscule placental anastomoses and has been reported to occur only in monochorionic twins [3]. However, this report shows that in rare cases, placental anastomoses can be present in dichorionic twins as well, potentially leading to TAPS and its associated severe consequences.

Although very uncommon, anastomoses in dichorionic twins have been described previously in 6 different case reports [4-9]. The majority of these cases (5/6) were identified because of the development of twin-twin transfusion syndrome (TTTS), and in all cases, superficial anastomoses could be detected at the placental surface. Recently, Zilliox et al. [10] probably described the first case of severe TAPS in a dichorionic twin. However, the definitive diagnosis was not confirmed with reticulocyte count measurements, and placental injection failed to show minuscule placental anastomoses, which are characteristic for TAPS. Whether the large placental vessels shown in the figure of the reported case by Zilliox et al. [10] truly represent vascular anastomoses is a matter of controversy (we suspect that this was not the case). We, therefore, present the first case of TAPS in a dichorionic twin, confirmed by the presence of a small deep-hidden $\mathrm{VV}$ anastomosis after placental injection. These case reports show that the distinction between monochorionic and dichorionic twins is not as strict as thought previously, and that in rare cases, anastomoses can also be present in dichorionic twins, potentially leading to feto-fetal transfusion pathology with severe consequences. Therefore, when a pale and plethoric twin pair is born, we recommend to perform a full diagnostic work-up to investigate the presence of a feto-fetal transfusion problem, regardless of the type of chorionicity of the twin pregnancy.

In case of a large intertwin hemoglobin difference, a distinction needs to be made between TAPS and acute peripartum TTTS. The diagnosis of TAPS is confirmed when at least 1 of the following criteria is met: a reticulocyte count ratio $>1.7$ (reticulocyte count donor/reticulo-

TAPS in a DC Twin Leading to Severe Cerebral Injury in the Recipient Twin cyte count recipient) representing reticulocytosis in the donor twin, or the presence of only small vascular anastomoses (diameter $<1 \mathrm{~mm}$ ) $[3,11]$. In acute peripartum TTTS, there is an abrupt transfusion through large bidirectional anastomoses (diameter $>1 \mathrm{~mm}$ ), without reticulocytosis in the donor twin (resulting in a reticulocyte ratio <1.7) [12]. It should be noted that in our case there was not enough information available to provide conclusive answers to these 2 criteria, but the data that we have indicate that TAPS is more likely than acute peripartum TTTS. First, although the reticulocyte count in the recipient twin was not measured, we found an increased reticulocyte count in the donor twin [13], corroborating the potential chronic nature of the transfusion. Moreover, this donor twin also demonstrated low platelet and leukocyte counts. Thrombocytopenia and leukopenia in TAPS donors have previously been described to occur and likely result from the suppression of WBCs and platelets production due to chronic anemia and increased erythropoiesis [14]. With placental injection, we were also able to confirm the presence of a deep-hidden VV anastomosis. Although suboptimal contrast-angiography prevented adequate examination of the size of this anastomosis, it is very likely that the diameter was small, as it took a long time and a lot of pressure to achieve full injection of the co-twin's venous circulation. Whether this anastomosis was the only one that caused the unbalanced transfusion or that other arteriovenous anastomoses contributed to the development of TAPS as well, will remain unknown. Previous literature has reported that in rare cases of TAPS only one VV anastomosis was present [15]. It is possible that a VV anastomosis might act like an AV anastomosis under certain circumstances. Last, the maternal side of the placenta of this case showed a color difference, concordant with anemia, and polycythemia in the infants. This color difference is only seen in TAPS placentas and not in placenta from twins with acute peripartum TTTS [16].

This case illustrates that the consequences of TAPS should not be underestimated. Although donor twins are at increased risk for perinatal mortality [15], TAPS recipients might also experience severe consequences of polycythemia, including limb ischemia and severe cerebral damage [17]. A case of extensive brain injury leading to fatal outcome in a TAPS recipient was previously reported by our study group in 2014 [18]. Moreover, the rate of long-term neurodevelopmental impairment in TAPS is high, with TAPS donors having a 15\% chance of hearing loss and a $34 \%$ of mild-to-severe cognitive impairment [19]. To timely detect and treat both short- and long-term morbidities of TAPS, we strongly recommend to perform 
cerebral ultrasound and neonatal hearing screening in the first days after birth and plan long-term follow-up appointments for both infants to monitor cognitive and motor development. In conclusion, this case report adds to the small body of knowledge of rare cases of feto-fetal transfusion in dichorionic twins and shows us that the clinical picture, rather than the established type of chorionicity, should be leading in medical decision-making regarding the required postnatal diagnostics and treatment.

\section{Statement of Ethics}

Written informed consent was obtained of both parents for the publication of this case report and accompanying images. The research complies with the guidelines for human studies and was conducted ethically in accordance with the World Medical Association Declaration of Helsinki.

\section{Conflict of Interest Statement}

The authors have no conflicts of interest to declare.

\section{Funding Sources}

There was no sponsorship or funding arranged for this case report.

\section{Author Contributions}

L.S.A. Tollenaar, S.A. Prins, S. Beuger, F. Slaghekke, D. Oepkes, and E. Lopriore have all contributed to the concept, writing, and revision of this manuscript.

\section{References}

1 Volpe JJ. Intraventricular hemorrhage and brain injury in the premature infant. Diagnosis, prognosis, and prevention. Clin Perinatol. 1989;16(2):387-411.

2 Levene MI. Measurement of the growth of the lateral ventricles in preterm infants with realtime ultrasound. Arch Dis Child. 1981;56(12): $900-4$.

3 Lopriore E, Middeldorp JM, Oepkes D, Kanhai HH, Walther FJ, Vandenbussche FP. Twin anemia-polycythemia sequence in two monochorionic twin pairs without oligopolyhydramnios sequence. Placenta. 2007; 28(1):47-51.

4 Cavazza MC, Lai AC, Sousa S, Pina R. Dichorionic pregnancy complicated by a twin-totwin transfusion syndrome. BMJ Case Rep. 2019;12(10):e231614.

5 Lage JM, Vanmarter LJ, Mikhail E. Vascular anastomoses in fused, dichorionic twin placentas resulting in twin transfusion syndrome. Placenta. 1989;10(1):55-9.

6 Lanna M, Faiola S, Casati D, Rustico MA. Twin-twin transfusion syndrome in dichorionic twin pregnancy: rare but not impossible. Ultrasound Obstet Gynecol. 2019;54(3):4178.

7 Quintero R, Kontopoulos EV, Barness E, Steffensen TS, Hilbelink D, Chmait R, et al. Twintwin transfusion syndrome in a dichorionicmonozygotic twin pregnancy: the end of a paradigm? Fetal Pediatr Pathol. 2010;29(2): 81-8.
8 Molnar-Nadasdy G, Altshuler G. Perinatal pathology casebook. A case of twin transfusion syndrome with dichorionic placentas. J Perinatol. 1996;16(6):507-9.

9 Foschini MP, Gabrielli L, Dorji T, Kos M, Lazzarotto T, Lanari M, et al. Vascular anastomoses in dichorionic diamniotic-fused placentas. Int J Gynecol Pathol. 2003;22(4):35961.

10 Zilliox M, Koch A, Favre R, Sananes N. Unusual twin anemia-polycythemia sequence in a dichorionic diamniotic pregnancy. J Gynecol Obstet Hum Reprod. 2019;48(5):359-61.

11 Lopriore E, Slaghekke F, Oepkes D, Middeldorp JM, Vandenbussche FP, Walther FJ. Hematological characteristics in neonates with twin anemia-polycythemia sequence (TAPS). Prenat Diagn. 2010;30(3):251-5.

12 Lopriore E, Holtkamp N, Sueters M, Middeldorp JM, Walther FJ, Oepkes D. Acute peripartum twin-twin transfusion syndrome: incidence, risk factors, placental characteristics and neonatal outcome. J Obstet Gynaecol Res. 2014;40(1):18-24.

13 Nicolaides KH, Thilaganathan B, Mibashan RS. Cordocentesis in the investigation of fetal erythropoiesis. Am J Obstet Gynecol. 1989; 161(5):1197-200.

14 Visser GL, Tollenaar LSA, Bekker V, Te Pas AB, Lankester AC, Oepkes D, et al. Leukocyte counts and other hematological values in twin-twin transfusion syndrome and twin anemia-polycythemia sequence. Fetal Diagn Ther. 2020;47(2):123-8.
15 Tollenaar LSA, Slaghekke F, Lewi L, Colmant C, Lanna M, Weingertner AS, et al. Spontaneous twin anemia polycythemia sequence: management and outcome in a large international cohort of 249 cases. Am J Obstet Gynecol. 2021 Feb;224(2):213.e1-e11.

16 Tollenaar LSA, Zhao DP, Middeldorp JM, Oepkes D, Slaghekke F, Lopriore E. Can color difference on the maternal side of the placenta distinguish between acute peripartum twin-twin transfusion syndrome and twin anemia-polycythemia sequence? Placenta. 2017;57:189-93.

17 Robyr R, Lewi L, Salomon LJ, Yamamoto M, Bernard JP, Deprest J, et al. Prevalence and management of late fetal complications following successful selective laser coagulation of chorionic plate anastomoses in twin-totwin transfusion syndrome. Am J Obstet Gynecol. 2006;194(3):796-803.

18 Lopriore E, Slaghekke F, Kersbergen KJ, de Vries LS, Drogtrop AP, Middeldorp JM, et al. Severe cerebral injury in a recipient with twin anemia-polycythemia sequence. Ultrasound Obstet Gynecol. 2013;41(6):702-6.

19 Tollenaar LSA, Lopriore E, Slaghekke F, Oepkes D, Middeldorp JM, Haak MC, et al High risk of long-term neurodevelopmental impairment in donor twins with spontaneous twin anemia-polycythemia sequence. Ultrasound Obstet Gynecol. 2020;55(1):39-46. 